\title{
Residue allelopathy in Parthenium hysterophorus L.- Does parthenin play a leading role?
}

\author{
Regina G. Belz ${ }^{a}$, Carl F. Reinhardt ${ }^{b}$, Llewellyn C. Foxcroft ${ }^{c}$ and Karl Hurle ${ }^{a}$ \\ ${ }^{a}$ University of Hohenheim (360), Department of Weed Science, 70593 Stuttgart, \\ Germany \\ ${ }^{b}$ University of Pretoria, Department of Plant Production and Soil Science, Pretoria 0002, \\ South Africa \\ ${ }^{\mathrm{c}}$ Scientific Services, Kruger National Park, P/Bag X402, Skukuza 1350, South Africa
}

\begin{abstract}
Apart from its competitive ability, the invasiveness of the noxious weed Parthenium hysterophorus L. is thought to be due to an ability to displace other species by means of allelopathy. The sesquiterpene lactone parthenin that is biosynthesized by this species is thought to play a role in its allelopathic interference with surrounding plants. However, despite the fact that parthenin is released from various plant parts into the soil, little is known about its relative contribution to overall allelopathic effects. Because leaf residues are believed to deliver large amounts of parthenin to soils during decomposition, we investigated the level of involvement of parthenin in overall phytotoxicity of decomposing leaf material in a South African population of $P$. hysterophorus. The natural release of inhibitors during decomposition was simulated by aqueous extraction of fresh leaf material (FM) and the responses of test plant species (Ageratum conyzoides L., Echinochloa crus-galli (L.) P. Beauv., Eragrostis curvula (Schrad) Nees, Eragrostis tef (Zucc.) Trotter, Lactuca sativa L.) to extracts were evaluated under laboratory conditions in dose-response bioassays. Species differed considerably in their sensitivity to leaf extracts, whereby $A$. conyzoides was most sensitive with $\mathrm{ED}_{50}$-values for root length of $24.8 \mathrm{mg} \mathrm{FM} / \mathrm{ml}$ and $53.6 \mathrm{mg} \mathrm{FM} / \mathrm{ml}$ for inhibition of germination. The quantities of
\end{abstract}


parthenin within leaf extracts were determined using HPLC, and the phytotoxicity of quantified extract concentrations was assessed in pure compound dose-response bioassays. A. conyzoides was again most sensitive, with $\mathrm{ED}_{50}$-values for inhibition of root length and germination by parthenin of 51.8 and $289.9 \mu \mathrm{g} / \mathrm{ml}$, respectively. Furthermore, parthenin treatments proved to significantly delay germination and stimulate root growth at low doses. The contribution of parthenin to observed effects of leaf extracts was finally estimated by model comparisons of dose-response relations of parthenin in leaf extracts or as a pure compound. Results showed that the contribution of parthenin was highly dependent on its concentration within extract solutions and varied between $16 \%$ and $100 \%$ of overall phytotoxicity of leaf extracts. The inhibition could be completely reproduced by pure parthenin treatments in quantified amounts, when extract solutions with high levels of parthenin were tested on the most sensitive species, $A$. conyzoides. This suggested that the release of parthenin during decomposition of leaf material has a potential to play a leading role for allelopathy in P. hysterophorus; however, its significance in a natural setting will very much rely on the amount of leaf material accumulated on soil surfaces and the concentration of parthenin in residues.

\section{Article Outline}

1. Introduction

2. Materials and methods

2.1. Phytotoxicity of aqueous leaf extracts

2.2. Phytotoxicity of pure parthenin

2.3. Contribution of parthenin

3. Results and discussion

3.1. Phytotoxicity of aqueous leaf extracts

3.2. Phytotoxicity of pure parthenin

3.3. Contribution of parthenin

4. Conclusions

Acknowledgements

References 


\section{Introduction}

The success of aggressive plant species to invade and establish new territories depends on their capacity to interfere with and replace other species. In the last century Parthenium hysterophorus L. has spread from its endemic habitat, mainly the region around the Gulf of Mexico including West Indies and presumably central Argentina (Towers et al., 1977; Picman and Towers, 1982), throughout the tropics and has become a serious problem in many parts of the world. The weed predominantly invades disturbed habitats, including agroecosystems, which may be largely attributable to its high adaptability and competitiveness under contrasting ecological and climatic conditions (Tower et al., 1977). Once established, $P$. hysterophorus can form dense, pure stands underneath plant residues, and seeds accumulate and render the soil unsuitable for other vegetation (Kanchan and Jayachandra, 1979a and Kanchan and Jayachandra, 1979b; Kohli and Batish, 1994). These observations, along with the fact that hardly any other vegetation invades those patches or its vicinity, lead to the assumption that allelopathy may be operative as well (Kachan and Jayachandra, 1979a; Kohli and Batish, 1994; Singh et al., 2003). Potential functions of aerial and underground parts of intact plants and their residues in allelopathy of $P$. hysterophorus have been investigated in numerous studies. Meanwhile, it has been established that $P$. hysterophorus releases phytotoxic compounds by root exudation (Kanchan and Jayachandra, 1979a and Kanchan and Jayachandra, 1980a), leaching from vegetative parts of living plants (Kanchan and Jayachandra, 1980a and Kanchan and Jayachandra, 1980b) as well as from the achene-complex (Picman and Picman, 1984; Reinhardt et al., 2004), and decaying plant residues (Kanchan and Jayachandra, 1980a and Kanchan and Jayachandra, 1980b; Pandey, 1994a, Pandey, 1994b, Pandey, 1993a and Pandey, 1993b; Kohli et al., 1996). Inhibitory effects could be demonstrated under laboratory conditions for each mode of toxin release.

However, soils infested with $P$. hysterophorus showed a maximum of inhibitory activity in the top soil $(0-7 \mathrm{~cm})$, which led to the assumption that leaching from intact leaves and decomposition of aerial plant parts may contribute strongly to the allelopathic potential of P. hysterophorus (Kohli and Batish, 1994). Investigations tracing the source of allelopathy in aerial plant parts isolated two major classes of putative water-soluble allelochemicals, phenolic acids and sesquiterpene lactones (Kanchan and Jayachandra, 
1980a). The most abundant of the inhibitors in the Indian population of $P$. hysterophorus studied by Kanchan and Jayachandra (1980a) was the sesquiterpene lactone parthenin (1,6 $\beta$-dihydroxy-4-oxo-10 $\alpha \mathrm{H}$-ambrosa-2,11(13)-dien-12-oic acid- $\gamma$-lactone), which is sequestered at high levels in capitate-sessile trichomes present on leaves, stems, and the achene-complex (Reinhardt et al., 2004). Capitate-sessile trichomes proved to contain almost $100 \%$ parthenin at a quantity of $2.4 \%$ of fresh weight and, thus, function as the main source of parthenin in P. hysterophorus. Because leaves carry most of the capitatesessile trichomes on the upper and lower surface, high levels of parthenin are found in leaves (Reinhardt et al., 2004). The sequestration in trichomes on the leaf surface allows parthenin to be easily released after rupture of trichomes by rain-wash or water, respectively and, thus, enter the soil via leaf leachates or decomposition of plant residues (Kanchan and Jayachandra, 1980a; Reinhardt et al., 2004). Parthenin has been shown to be released in both fashions; however, most indications for allelopathy suggest release from leaf residues. Utilization of aqueous extraction to simulate the natural release of parthenin during decay, removed approximately one tenth of the total amount present in the leaves within $24 \mathrm{~h}$ (Reinhardt et al., 2004). Reports on the phytotoxic activity of such aqueous, parthenin-containing leaf extracts are numerous (e.g., Kanchan and Jayachandra, 1980a and Kanchan and Jayachandra, 1980b; Pandey, 1994a, Pandey, 1994b, Pandey, 1993a and Pandey, 1993b; Kohli et al., 1996) and the phytotoxicity of parthenin on various plants is also well documented (Pandey, 1994a and Pandey, 1996; Batish et al., 1997, Batish et al., 2002a and Batish et al., 2002b; Datta and Saxena, 2001). Nevertheless, it is not known if the limited water-solubility of parthenin allows for increased phytotoxicity, and the relative role of parthenin in residue allelopathy of $P$. hysterophorus is also unclear.

The main objective of this study was to investigate if the release of parthenin during decomposition of leaf material is a determining causal factor for overall phytotoxicity of biologically active compounds located in and on the leaves of $P$. hysterophorus. The natural release of inhibitors during decomposition was studied in a population occurring in South Africa and simulated by aqueous extraction of fresh leaf material. The phytotoxicity of obtained extracts was assessed on five different plant species in doseresponse bioassays. Simultaneously, the quantities of extracted parthenin were measured 
using high-performance liquid chromatography (HPLC), and their capacity to account for observed effects investigated in pure compound dose-response bioassays. Finally, the contribution of parthenin was statistically estimated by model comparisons of doseresponse relations obtained for the response of test plant species to parthenin as quantified in leaf extracts or applied as pure compound.

\section{Materials and methods}

\subsection{Phytotoxicity of aqueous leaf extracts}

Plants of P. hysterophorus (seeds collected at Skukuza in the Kruger National Park, South Africa) were germinated under greenhouse conditions $\left(15 / 9 \mathrm{~h}, 22 / 18{ }^{\circ} \mathrm{C}\right.$, $300 / 0 \mu \mathrm{E} / \mathrm{m}^{2} \mathrm{~s}$ ) at the University of Hohenheim (Germany) in a one-by-one mixture (v/v) of quartz sand and garden soil (Humusoil, Floragard, Germany). Fresh leaf material for the preparation of aqueous extracts was harvested three times during a ten week growth period, cut into $\approx 1 \mathrm{~cm}^{2}$ segments, and frozen at $-20{ }^{\circ} \mathrm{C}$ until used. Extraction was performed separately for each harvest at room temperature in the dark over a period of $24 \mathrm{~h}$ using deionized water [200 $\mathrm{mg}$ fresh leaf material (FM) per $\mathrm{ml}$ water]. The extract was filtered twice $\left(589^{3}\right.$ blue ribbon, Schleicher \& Schuell, Germany) and subsequently filter sterilized [Chromafil PET-20/25 (0.2 $\mu \mathrm{m})$, Macherey-Nagel, Germany]. The pH of this initial extract was adjusted with $1 \mathrm{M} \mathrm{HCl}$ to the $\mathrm{pH}$ of deionized water $(\mathrm{pH}=6.3)$, which was later used to prepare a dilution series (0-200 mg FM/ml). Control treatments used deionized water only. Germination assays were conducted using glass Petri dishes (4.5 cm in diam.) with two dicotyledonous (Ageratum conyzoides L., Lactuca sativa L. var. capitata) and three monocotyledonous species (Eragrostis curvula (Schrad.) Nees, Eragrostis tef (Zucc.) Trotter, Echinochloa crus-galli (L.) P. Beauv.). One to three species were tested at a harvest time. At each treatment, 15 seeds were placed on one layer of filter paper (Rundfilter 595, Schleicher \& Schuell, Germany) and exposed to $2 \mathrm{ml}$ of the aqueous leaf extract. Each treatment was replicated six times. Petri dishes were sealed with parafilm and cultivated in a completely randomized design in a growth chamber $\left(12 / 12 \mathrm{~h}, 24 / 18^{\circ} \mathrm{C}, 50 / 0 \mu \mathrm{E} / \mathrm{m}^{2} \mathrm{~s}\right)$. After seven days, radicle length $(\geqslant 1 \mathrm{~mm})$ and germination were recorded. Dose-response curves were calculated using the logistic response function of Streibig (1988) based on Finney (1978) or its peaked expansion 
(Brain and Cousens, 1989; Schabenberger et al., 1999). Mathematical modeling was performed using nonlinear regression analysis with SPSS ${ }^{\circledR}$ regression models [method of Levenberg-Marquardt (Marquardt, 1963), 1/ $\mathrm{e}^{8}$ convergence of error sum of squares]. The quality of curve fitting was assessed by $F$ test for lack-of-fit based on analysis of variance $(P=0.05)$. Significance of hormesis was assessed by calculation of the $95 \%$ confidence intervals for the estimate of the initial rate of increase at low densities $(F)$ and was given for $F>0$. Comparison of dose-response curves was done by horizontal assessment ( $F$ test, $\alpha=0.05$ ). If response curves differed significantly in asymptotes, response measurements were normalized by the lower and upper asymptotes according to Streibig et al. (1995). In order to quantify the amount of parthenin in aqueous extracts, an aliquot $[950+50 \mu \mathrm{l}$ acetonitrile (ACN)] of the initial extract (200 $\mathrm{mg} \mathrm{FM} / \mathrm{ml}$ ) was centrifuged (15 min, 14,000 rpm) and analyzed by HPLC (Waters model chromatograph) with DAD detection (photodiode array detector, Waters 991). A Synergi polar C-18 reversed phase column [250 $\mathrm{mm}$ by $4.6 \mathrm{~mm}(4 \mu \mathrm{m})$, Phenomenex, Germany] was used, and eluted with a gradient of $5 \% \mathrm{ACN}$ and $95 \% \mathrm{Na}_{2} \mathrm{HPO}_{4}$-buffer $(1 \mathrm{mM}, \mathrm{pH} 2.4,10 \% \mathrm{ACN})$ for $0-8 \mathrm{~min}$ $\left(0.65 \mathrm{ml} / \mathrm{min}\right.$ flow rate), $30 \% \mathrm{ACN}$ and $70 \% \mathrm{Na}_{2} \mathrm{HPO}_{4}$-buffer for $8-26 \mathrm{~min}(0.7 \mathrm{ml} / \mathrm{min}$ flow rate), $100 \% \mathrm{ACN}$ for $26-29 \mathrm{~min}(0.7 \mathrm{ml} / \mathrm{min}$ flow rate), $100 \% \mathrm{ACN}$ for $29-31 \mathrm{~min}$ $(0.7 \mathrm{ml} / \mathrm{min}$ flow rate), then reequilibrated to starting conditions. Injection volume was $25 \mu 1$. Parthenin was identified and quantified at $220 \mathrm{~nm}$ using external calibration curves.

The isolation of purified standards of parthenin was done from organic extracts of the leaf surface of $P$. hysterophorus plants. Extracts were obtained by dipping fresh leaf material for $10 \mathrm{~s}$ in tert-butyl methyl ether ( $250 \mathrm{mg} \mathrm{FM} / \mathrm{ml}$ TBME). The extracts were subsequently filtered over anhydrous sodium sulphate and evaporated to near dryness under vacuum. The residue was redissolved in a one-by-one mixture $(\mathrm{v} / \mathrm{v})$ of $\mathrm{ACN}$ and water and fractionated by preparative HPLC (Varian model chromatograph) with UV detection (Varian UV-VIS detector model 345; detection wavelength 225/254 nm). A Grom Nucleosil $120 \mathrm{C} 4$ column [250 mm by $16 \mathrm{~mm}(5 \mu \mathrm{m})$, Grom, Germany] was used, and eluted with a gradient of $20 \% \mathrm{ACN}$ and $80 \% \mathrm{Na}_{2} \mathrm{HPO}_{4}$-buffer $(1 \mathrm{mM}, \mathrm{pH} 3,10 \%$ $\mathrm{ACN}$ ) for 0-20 $\mathrm{min}, 100 \% \mathrm{ACN}$ for $20-26 \mathrm{~min}$, then reequilibrated to starting conditions ( $6 \mathrm{ml} / \mathrm{min}$ flow rate). Injection volume was $100 \mu \mathrm{l}$. Parthenin was identified in the 
fraction ranging from 9.1-10.3 min. Purity of standards was verified by HPLC-DAD and results confirmed by HPLC-ESI--MS.

\subsection{Phytotoxicity of pure parthenin}

The phytotoxicity of parthenin was studied in dose-response bioassays that used the same experimental design as the germination assays with aqueous leaf extracts. Parthenin was dissolved in deionized water containing 1\% acetone as solvent and tested at 12 different concentrations $(0-500 \mu \mathrm{g} / \mathrm{ml})$ with six replications. Controls were performed with acetone only. Isolation of parthenin for bioassays was performed using organic extracts of the leaf surface of $P$. hysterophorus plants (250 mg FM/ml TBME dipped for $10 \mathrm{~s}$ ). Vacuum concentrated extracts were redissolved in TBME and parthenin crystallized after heating $\left(40^{\circ} \mathrm{C}\right)$ by addition of small amounts of 2,2,4-trimethylpentane. After the supernatant was removed, parthenin crystals were washed twice with TBME and finally dried with nitrogen gas. Purity of isolated parthenin was checked by HPLC-DAD analysis $(\geqslant 95 \%)$. After seven days of cultivation, radicle length ( $\geqslant 1 \mathrm{~mm}$ ) and germination was recorded and dose-response curves calculated as described. In case of $L$. sativa, germination was measured daily.

\subsection{Contribution of parthenin}

In order to quantify the contribution of parthenin to the observed overall phytotoxicity of aqueous leaf extracts, the observed response of the test plant species at different extract concentrations was curve-fitted to the respective content of parthenin quantified. The obtained response curves were then compared to pure parthenin treatments using the lack-of-fit $F$ test ( $\alpha=0.05$ ). The contribution of parthenin was finally derived from the relative potency $R$, which is a measure for the horizontal displacement of the curves along the $x$-axis and represents the quotient between doses of two treatments giving similar responses. $R$ was calculated at the $50 \%$ response level $\left(\mathrm{ED}_{50}\right)$ :

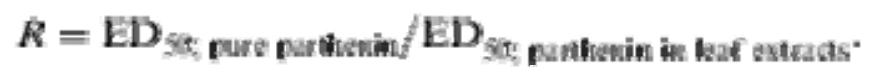




\section{Results and discussion}

\subsection{Phytotoxicity of aqueous leaf extracts}

Species varied considerably in their sensitivity to aqueous extracts of $P$. hysterophorus for both root growth and germination (Table 1). Species-specific differences in the sensitivity to aqueous extracts of fresh or dry leaf material of $P$. hysterophorus were reported in previous studies (e.g., Srivastava et al., 1985; Mersie and Singh, 1987; Kohli et al., 1996).

Table 1.

Phytotoxicity of aqueous leaf extracts of Parthenium hysterophorus on five different plant species

\begin{tabular}{|l|l|l|}
\hline Species & \multicolumn{2}{|l|}{$\mathbf{E D}_{\mathbf{5 0}}{ }^{\mathbf{a}}$ [mg/ml $\left.^{\mathbf{b}}\right]$} \\
\hline & root length & Germination \\
\hline Ageratum conyzoides & $24.8(20.9-28.8)^{\mathbf{c}}$ & $53.6(43.7-63.6)$ \\
\hline Echinochloa crus-galli & $52.4(42.5-62.2)$ & $228.2(152.4-303.4)$ \\
\hline Eragrostis curvula & $52.2(42.0-62.5)$ & $150.7(119.6-181.8)$ \\
\hline Eragrostis tef & $65.2(53.1-77.4)$ & $125.1(105.1-145.1)$ \\
\hline Lactuca sativa & $95.5(82.8-108.1)$ & $226.9(173.6-280.1)$ \\
\hline
\end{tabular}

${ }^{a}$ Extract concentration causing 50\% response.

${ }^{\mathrm{b}}$ Amount of fresh leaf material extracted for $24 \mathrm{~h}$ per $\mathrm{ml}$ water.

${ }^{c}$ Asymptotic 95\% confidence interval.

Dose-response curves for root length were parallel (average slope $B=2.7$ ), but differed significantly in $\mathrm{ED}_{50}$-values. Most sensitive was $\mathrm{A}$. conyzoides with an $\mathrm{ED}_{50}$-value for root length of $24.8 \mathrm{mg} / \mathrm{ml}$, which was almost four times lower than the dose level necessary to give the same response on the most insensitive species $L$. sativa. The three monocotyledonous species E. crus-galli, E. curvula, and E. tef did not significantly differ in $\mathrm{ED}_{50}$-values with an average of $56.4 \mathrm{mg} / \mathrm{ml}$. In addition to described inhibitory effects on root length, low doses of aqueous leaf extracts stimulated root growth at almost all 
species tested. However, the stimulatory effect was statistically significant only in case of E. tef (Fig. 1a). Maximum stimulation of root growth of E. tef occurred at $18.0 \mathrm{mg} / \mathrm{ml}$ ( $144 \%$ of control) and the hormetic effect disappeared at doses $>40.0 \mathrm{mg} / \mathrm{ml}$. Stimulatory effects of aqueous extracts of residues of $P$. hysterophorus on growth of different target species were previously observed either at low doses of applied extracts as in the present case, or after recovery of initially affected plants when the inhibitory activity of residues declined (Kanchan and Jayachandra, 1979b; Pandey, 1993a and Pandey, 1993b). In both cases, hormesis can be caused by low, subinhibitory levels of phytotoxic compounds and/or nutrients leached from residues. Even at the current short extraction period, a contribution of nutrients to the observed hormetic effects at low extract concentrations cannot be excluded, since low levels of nutrients can promote the root growth of test plant species as well (Belz and Hurle, 2004). At present, it remains speculative what caused observed stimulatory effects.

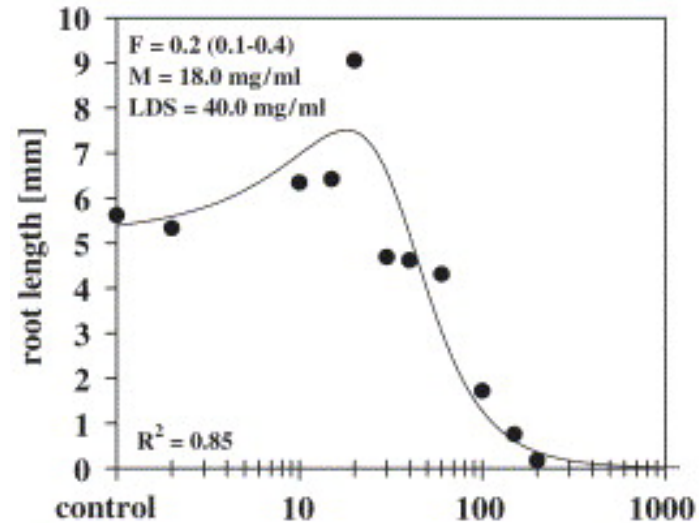

(a) leaf extract concentration $\left[\mathrm{mg} / \mathrm{ml}^{a}\right]$

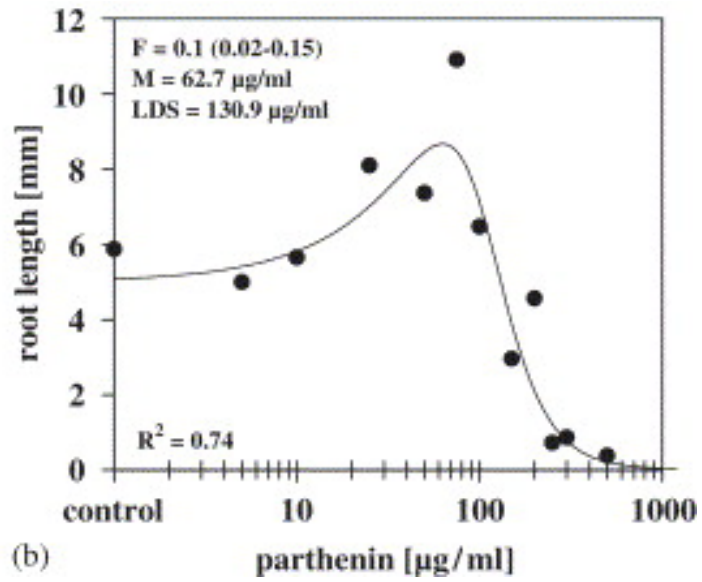

Fig. 1. Stimulation of root growth of Eragrostis tef at low doses of aqueous leaf extracts of Parthenium hysterophorus (a) and of Eragrostis curvula at low doses of parthenin (b). $\mathrm{F}=$ initial rate of increase in response (asymptotic 95\% confidence interval in parentheses); $\mathrm{M}=$ dose giving maximum response; $\mathrm{LDS}=$ limited dose for stimulation; $R^{2}=1$-residual SS/corrected SS; ${ }^{a}$ amount of fresh leaf material extracted for $24 \mathrm{~h}$ per ml water.

As evident for root length, the dose-response curves for germination were parallel for all species (average $B=2.6$ ), but differed in $\mathrm{ED}_{50}$-values. $A$. conyzoides was most sensitive with an $\mathrm{ED}_{50}$-value for germination of $53.5 \mathrm{mg} / \mathrm{ml}$, which was more than four times 
lower than the average $\mathrm{ED}_{50}$-value for the two most insensitive species E. crus-galli and L. sativa (average $\mathrm{ED}_{50}=228.9 \mathrm{mg} / \mathrm{ml}$ ). The response curves of $E$. curvula and $E$. tef did not significantly differ (average $\mathrm{ED}_{50}=134.7 \mathrm{mg} / \mathrm{ml}$ ). While the highest extract concentration almost completely inhibited root growth in all species tested, a complete lack of germination was only observed in case of $A$. conyzoides exposed to extract concentrations $\geqslant 100 \mathrm{mg} / \mathrm{ml}$. This along with the species-specific relative potencies $R$ for the response curves of both parameters measured (average $R=2.8 \pm 0.7$ ) clearly shows that after seven days aqueous leaf extracts of $P$. hysterophorus were almost three times more active on root growth of different test species than on germination. A similar lower sensitivity of germination up to no observable effect compared to root growth was reported for several species in response to aqueous extracts of $P$. hysterophorus (e.g., Srivastava et al., 1985; Singh and Sangeeta, 1991; Kohli et al., 1996). As test plants growing on agricultural fields previously infested with $P$. hysterophorus showed the same phenomenon (Kohli and Batish, 1994), it is to conclude that growth inhibition of competing neighbors is more significant for allelopathy of decomposing residues of $P$. hysterophorus than reducing their number by inhibition of germination. On the other hand, Kohli et al. (1996) observed that even if no inhibition in germination by leaf extracts occurred, the initiation of germination was considerably delayed for species such as Cyamopsis tetragonoloba (L.) Taub. or Trifolium alexandrinum L. Delayed germination was also reported from investigations with infested soils (Kohli and Batish, 1994). Such germination-impacting effects on receiver species can provide an important competitive advantage for the allelopathic donor and could be as important as allelopathic growth inhibition itself. In the case of $P$. hysterophorus aqueous extracts of the achenecomplex showed germination delaying effects involving the plant itself (Picman and Picman, 1984), and because the same putative inhibitors as in leaves occurred in the achene-complex (Kanchan and Jayachandra, 1980a), it is likely that decaying leaf residues will delay donor germination as well. Along with the fact that autotoxicity has also been reported for the growth of P. hysterophorus (Kumari and Kohli, 1987), the benefits of delayed germination and growth inhibition of receiver species for the interference capacity of $P$. hysterophorus will depend considerably on the level of 
autotoxicity. Picman and Picman (1984) concluded that the sesquiterpene lactones which can be released by different plant parts are most important as autotoxins for germination. In the present study, the HPLC-DAD analysis detected parthenin and traces of coronopilin in all aqueous leaf extracts of $P$. hysterophorus with an average content of parthenin of $251.2 \mu \mathrm{g} / \mathrm{ml}$ extract at $200 \mathrm{mg} \mathrm{FM} / \mathrm{ml}$. This amounted to an average content of extractable parthenin in the fresh leaf material of $1.3 \mu \mathrm{g} / \mathrm{mg}$, which is in accordance with similar extract analyses of Reinhardt et al. (2004). The appearance of the two sesquiterpene lactones is in accordance with findings of Picman and Towers (1982), who classified the populations of $P$. hysterophorus in South Africa into the 'parthenin race', which is characterized by a sesquiterpene lactone composition composed of parthenin as major component, coronopilin, and tetraneurin-A. Thus, it is likely that tetraneurin-A was also present in the extracts currently studied. The relatively low amount of parthenin extractable by water at once, as compared to the total amount of parthenin present in leaves (Reinhardt et al., 2004), suggests a continuous release of low amounts of parthenin during decomposition over a prolonged period of time, mainly depending on the amount of moisture. If such low amounts of parthenin within extracts could be of a magnitude sufficient to provide phytotoxicity was assessed by pure parthenin treatments at quantified extract concentrations.

\subsection{Phytotoxicity of pure parthenin}

As observed with leaf extracts, test plant species differed significantly in their response to parthenin (Table 2). Dose-response curves for root growth were parallel (average $B=3.2$ ) with the exception of the most susceptible species $A$. conyzoides $(B=1.6)$. The significantly shallower slope might be attributed to its relatively slow germination and seedling development. Root growth of $A$. conyzoides $\left(\mathrm{ED}_{50}=51.8 \mu \mathrm{g} / \mathrm{ml}\right)$ was more than six times more sensitive compared to the most insensitive species L. sativa. The three monocotyledonous species showed a medium sensitivity, whereby E. curvula was most sensitive. E. crus-galli and E. tef did not significantly differ in $\mathrm{ED}_{50}$ (average $\mathrm{ED}_{50}=221.3 \mu \mathrm{g} / \mathrm{ml}$ ). This sequence of sensitivity coincides with the observed sensitivity to the parthenin-containing leaf extracts. However, in comparison to other allelochemicals tested under similar conditions, the phytotoxicity of parthenin seems 
moderate [e.g. isothiocyanates (Petersen et al., 2001), benzoxazolin-2(3H)-one (Belz and Hurle 2004)]. Low concentrations of parthenin promoted root growth at all species, and the hormetic effect was significant for E. crus-galli and E. curvula [average $F=0.10$ (0.05- 0.16 ; $95 \%$ confidence interval); Fig. 1b]. The maximum root length $(182 \%$ of control for E. curvula; $124 \%$ for E. crus-galli) appeared consistently at a parthenin concentration of $59.0 \mu \mathrm{g} / \mathrm{ml}(46.2-71.7 ; 95 \%$ confidence interval) and the hormetic effect disappeared at concentrations exceeding $124.7 \mu \mathrm{g} / \mathrm{ml}$ (107.2-142.2). A slight promotion in root length at low parthenin concentrations was previously found for Triticum aestivum L. by Batish et al. (1997). Relating the hormetic effect of leaf extracts on E. tef on the content of parthenin $(2.4 \mu \mathrm{g} / \mathrm{mg}$ FM; Fig. 1a) gives a M value of $43.2 \mu \mathrm{g} / \mathrm{ml}$ and a LDS value of $96.0 \mu \mathrm{g} / \mathrm{ml}$. Both values are close to the lower limits of the $95 \%$ confidence intervals for estimates of pure parthenin treatments on the monocotyledonous species. This suggests that the observed stimulatory effects of leaf extracts of $P$. hysterophorus were probably mostly attributable to parthenin, although in general the hormetic effect was less pronounced for parthenin in leaf extracts. At present, it remains speculative as to what masked the hormetic effect of parthenin in leaf extracts. Synergistic effects among extract constituents could have enhanced the phytotoxicity of parthenin, or other extract constituents with greater phytotoxicity could have interfered with parthenin hormesis. Table 2.

Phytotoxicity of parthenin on five different plant species

\begin{tabular}{|c|c|c|}
\hline \multirow[t]{2}{*}{ Species } & \multicolumn{2}{|l|}{$\mathrm{ED}_{50}{ }^{\mathrm{a}}[\mu \mathrm{g} / \mathrm{ml}]$} \\
\hline & root length & Germination \\
\hline Ageratum conyzoides & $51.8(38.7-64.8)^{\mathbf{b}}$ & $289.9(253.7-326.2)$ \\
\hline Echinochloa crus-galli & $220.6(200.8-240.4)$ & $645.8(514.3-777.2)$ \\
\hline Eragrostis curvula & $167.8(146.0-189.7)$ & $491.3(396.2-586.3)$ \\
\hline Eragrostis tef & $226.7(200.6-252.8)$ & $687.5(211.5-1163.5)$ \\
\hline Lactuca sativa & $328.4(296.4-360.3)$ & $450.4(399.4-501.5)$ \\
\hline
\end{tabular}


${ }^{\mathrm{a}}$ Concentration causing 50\% response.

${ }^{\mathrm{b}}$ Asymptotic $95 \%$ confidence interval.

The effects of parthenin on germination were on average more than three times lower. Stronger effects of parthenin on root growth than on germination were previously reported by Batish et al., 1997 and Batish et al., 2002b. In the present study, only the germination of $A$. conyzoides was noticeably inhibited $\left(\mathrm{ED}_{50}=289.9 \mu \mathrm{g} / \mathrm{ml}\right)$. For the other test plant species, the $\mathrm{ED}_{50}$-values were near or even greater than the highest concentration tested $(500 \mu \mathrm{g} / \mathrm{ml})$, indicating that parthenin is not even a weak germination inhibitor. Inhibition of germination by several phenolic acids, the second major class of putative allelochemicals in leaf extracts, is relatively low as well (Olofsdotter et al., 2002), which would be in accordance with our observed low phytotoxicity of extracts on germination.

However, evaluating the dynamics of germination for $L$. sativa as affected by parthenin showed a significant delay at day two of the bioassay with an almost five times lower $\mathrm{ED}_{50}$-value $\left(\mathrm{ED}_{50}=111.9 \mu \mathrm{g} / \mathrm{ml}\right)$ compared to the final evaluation on day seven $\left(\mathrm{ED}_{50}=544.3 \mu \mathrm{g} / \mathrm{ml}\right.$ ) (Fig. 2a). The response curve was significantly shallower in slope at day two $(B=1.5)$, while a prolongation of the time of exposure steepened the curve and lowered the measurable phytotoxicity up to days four to seven where no statistically significant differences occurred between response curves. Accordingly, sampling time, slope $\mathrm{B}$, and $\mathrm{ED}_{50}$-values showed a strong positive association (Fig. 2b). The fact that a delay in germination was observed both with pure parthenin treatments and parthenincontaining leaf extracts (Kohli et al., 1996), suggest that this sesquiterpene lactone could be a major delaying factor. A delay in germination makes assay-to-assay comparisons of effective doses difficult, especially with different lengths of exposures, whether germination or growth parameters are evaluated. It seems likely that this periodic dynamic may be the reason for the disparate effective doses for the inhibition of $A$. conyzoides by parthenin as observed in previous studies by Batish et al. (1997) (approximately $20 \mu \mathrm{g} / \mathrm{ml}$ for root length and germination) compared to our own results, since they evaluated the day three inhibition by parthenin. 

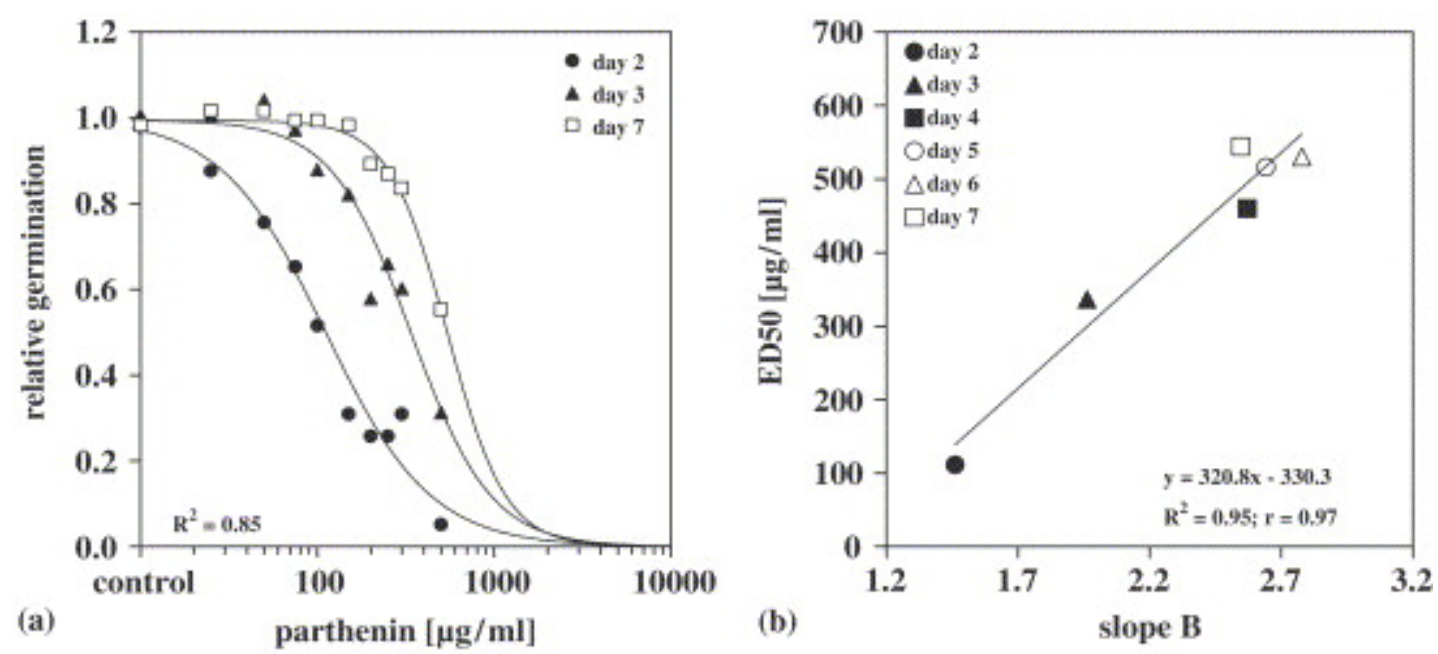

Fig. 2. Phytotoxicity of parthenin on germination of Lactuca sativa depending on the time after exposure (a) and the association between $\mathrm{ED}_{50}$ (dose causing 50\% reduction in germination) and slope $\mathrm{B}$ of normalized dose-response curves (b). $R^{2}=$ coefficient of determination; $r=$ Pearson correlation coefficient (significant at $P=0.01$ ).

Results revealed a significant decrease in inhibition of germination by parthenin with increasing time of exposure, which suggests that the currently applied length of exposure (7 days) was too long to have captured a considerable effect on germination for most test plant species. This indicates that the phytotoxicity of parthenin is characterized by a widely reversible inhibition of germination leading to a significant delay even at low concentrations, as well as growth stimulation at low, and inhibition at higher doses. Therefore, the subsequent comparison between the phytotoxicity of pure parthenin and the quantified contents of parthenin in the aqueous leaf extracts of $P$. hysterophorus considered merely root length as being the more reliable response parameter to estimate the role of parthenin.

\subsection{Contribution of parthenin}

The relation between the dose-response curves calculated for pure parthenin and for quantified amounts of parthenin in aqueous leaf extracts were parallel displaced to higher doses for pure parthenin at almost all species (Table 3). Pure parthenin treatments at concentrations quantified in the aqueous leaf extracts failed to achieve a similar response as observed for aqueous leaf extracts and were less phytotoxic. This suggests that parthenin does not exclusively account for the allelopathic potential of decomposing leaf 
material of $P$. hysterophorus and supports the assumption derived from observed hormetic effects, that parthenin acts jointly with extract constituents that enhance its phytotoxicity or have greater toxicity. Calculating the relative potency $R$, a measure for the horizontal displacement of the curves along the $x$-axis, showed fairly different values depending on the species tested and in particular the extracted leaf material. Three experiments were conducted with 1-3 test plant species at a time and although the extracted leaf material originated from the same $P$. hysterophorus plants that were continuously harvested, the amounts of parthenin in the aqueous leaf extracts differed considerably between experiments. Sources of variation are speculative, but may have been primarily plant age-dependent. The amount of extractable parthenin was highest where $A$. conyzoides, E. curvula, and E. tef were tested $(2.4 \mu \mathrm{g} / \mathrm{mg}$ FM). The average relative potency $R$ was $1.2 \pm 0.2$ and, thus, on average $>80 \%$ of the observed phytotoxicity of the leaf extracts on root growth could be explained by pure parthenin treatments. In case of the most sensitive species in bioassay, A. conyzoides, parthenin accounted for $100 \%$ of the observed effects on root growth, and there were no significant differences between dose-response curves. E. crus-galli and L. sativa were tested on leaf extracts containing less than half as much parthenin $(1.1 \mu \mathrm{g} / \mathrm{mg}$ FM). The resulting average relative potency $R=3.5 \pm 0.4$ estimated the contribution of parthenin at approximately $30 \%$. The last bioassay used the most sensitive species, $A$. conyzoides, tested at the lowest amount of extractable parthenin $(0.3 \mu \mathrm{g} / \mathrm{mg} \mathrm{FM})$. Although the dose-response curve fitted to leaf extract concentration did not significantly differ from the first experiment (average $\mathrm{ED}_{50}=25.6 \mathrm{mg} \mathrm{FM} / \mathrm{ml}$ ), the relative potency amounted to $R=6.2$ and estimated the contribution of parthenin at only $16 \%$ in contrast to $100 \%$ in the preceding experiment. This clearly showed that the contribution of parthenin to the overall phytotoxicity of leaf extracts was highly dependent on the concentration of parthenin within extract solutions. Correlating the log-transformed data of species specific $R$-values with the amount of extracted parthenin revealed a strong negative association (Pearson correlation coefficient -0.97) (Fig. 3). Thus, the higher the leaf extract concentration of parthenin, the lower the relative potency $R$, and the higher the contribution of parthenin. 
Table 3.

Contribution of parthenin to the overall phytotoxicity of aqueous leaf extracts of

Parthenium hysterophorus on root growth of five different species

\begin{tabular}{|c|c|c|c|c|}
\hline & & Response to & Presumed response to & Relative \\
\hline Species & Bioassay $^{a}$ & $\begin{array}{l}\text { pure } \\
\text { parthenin }\end{array}$ & $\begin{array}{l}\text { parthenin in leaf } \\
\text { extracts }\end{array}$ & potency \\
\hline & & $\operatorname{ED}_{50}{ }^{b}[\mu \mathrm{g} / \mathrm{ml}]$ & $\mathrm{ED}_{50}^{\mathrm{c}}[\mu \mathrm{g} / \mathrm{ml}]$ & $R^{\mathrm{d}}$ \\
\hline Ageratum conyzoides & $\mathrm{A}$ & $54.0 \mathrm{a}$ & $57.0 \mathrm{a}$ & 1.0 \\
\hline Eragrostis curvula & A & $173.4 \mathrm{a}$ & $127.9 \mathrm{~b}$ & 1.4 \\
\hline Eragrostis tef & A & $225.2 \mathrm{a}$ & $161.1 \mathrm{~b}$ & 1.4 \\
\hline $\begin{array}{l}\text { Echinochloa crus- } \\
\text { galli }\end{array}$ & $\mathrm{B}$ & $217.4 \mathrm{a}$ & $56.0 \mathrm{~b}$ & 3.9 \\
\hline Lactuca sativa & $\mathrm{B}$ & $329.7 \mathrm{a}$ & $103.6 \mathrm{~b}$ & 3.2 \\
\hline Ageratum conyzoides & $\mathrm{C}$ & $54.0 \mathrm{a}$ & $8.8 \mathrm{~b}$ & 6.2 \\
\hline
\end{tabular}

${ }^{a}$ Species tested within the same experiment.

${ }^{\mathrm{b}}$ Concentration causing $50 \%$ response in root length.

${ }^{\mathrm{c}} \mathrm{ED}_{50}$-values based on parthenin content of leaf extracts.

${ }^{\mathrm{d}}$ Ratio of $\mathrm{ED}_{50}$-values of parallel response curves; small letters indicate significant differences ( $F$ test, $\alpha=0.05$ ). 


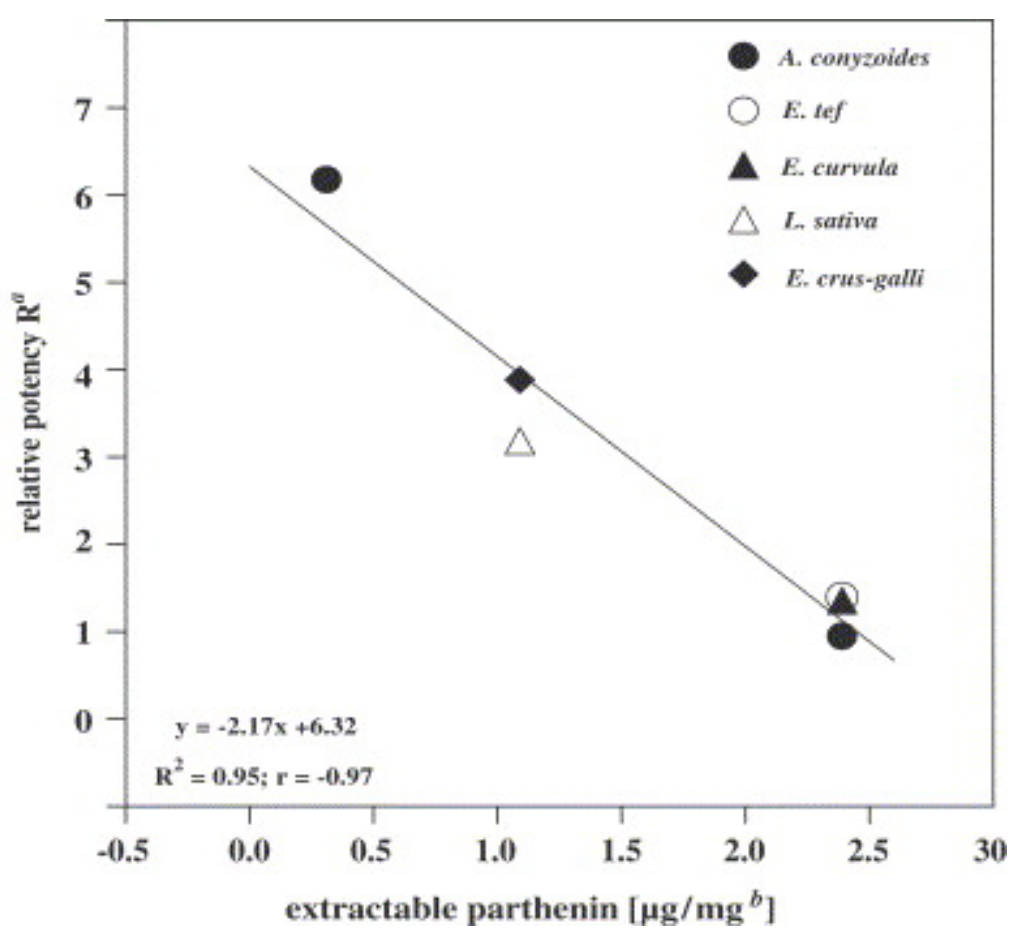

Fig. 3. Association between the amounts of parthenin extracted from leaves of

Parthenium hysterophorus and its contribution to the overall phytotoxicity of aqueous leaf extracts on five different plant species; ${ }^{a}$ ratio of $\mathrm{ED}_{50}$-values of dose-response curves of pure parthenin and parthenin in leaf extracts; ${ }^{b}$ amount of parthenin extracted by water from fresh leaves of $P$. hysterophorus within $24 \mathrm{~h} ; R^{2}=$ coefficient of determination; $r=$ Pearson correlation coefficient (significant at $P=0.01$ ).

Parthenin was isolated as one of the most important phytotoxins in the leaf material of $P$. hysterophorus, however, other toxic, water-soluble metabolites were present as well. Kanchan and Jayachandra (1980a) isolated several organic and phenolic acids, with phydroxybenzoic acid being most phytotoxic (Pandey et al., 1993a; Pandey, 1994a). Furthermore, although the amounts of other sesquiterpene lactones in the leaf material, in particular coronopilin and tetraneurin-A for the 'parthenin race', are comparably low (Picman et al., 1980; Picman and Towers, 1982), they could have contributed to the observed effects. Considering the apparent variable portion of parthenin within leaf extracts, that in case of $A$. conyzoides did not change the overall phytotoxicity of leaf extracts, it is most likely that a fluctuating phytotoxic mixture of sesquiterpene lactones and phenolic acids was responsible for the observed effects. The relative contribution of each of the individual compounds will depend on the qualitative and quantitative 
composition of metabolites in P. hysterophorus which may change depending on the developmental stage, the plant organ or population studied, and environmental factors. De la Fuente et al. (2000), for example, observed differences in the sequiterpene lactone composition and suggested an adaptive response to various physical and biotic factors. Variations in the composition of sesquiterpene lactones were also observed as a result of the origin of $P$. hysterophorus populations (Picman and Towers, 1982). Kanchan and Jayachandra (1980a) observed qualitative differences in the composition of sesquiterpene lactones and phenolic acids depending on the plant organ. Parthenin, followed by vanillic acid and caffeic acid were the most abundant inhibitors in the aerial parts of $P$. hysterophorus, while roots contained only traces of parthenin with phenolic acids as the major phytotoxic metabolites. Thus, the contribution of parthenin to allelopathy of decomposing root residues or perhaps also root exudates may be rather limited. Regarding the variability in the natural chemistry of $P$. hysterophorus, it seems questionable to quantify a definite level of contribution of parthenin to overall phytotoxicity that encompasses all potential situations. However, the current results show that parthenin contributed to the overall phytotoxic effects observed in this bioassay, although the level of contribution was highly variable depending on the proportion of parthenin in the aqueous extracts. When extract solutions with high levels of parthenin were tested on the most sensitive species in bioassay A. conyzoides, the phytotoxicity of leaf extracts could be completely reproduced at similar parthenin concentrations. Therefore, all factors that favor enhanced extraction of parthenin from plant materials will enhance the importance of this phytotoxin with respect to allelopathic potential in $P$. hysterophorus.

\section{Conclusions}

The release of parthenin by aqueous extraction of fresh leaf material of $P$. hysterophorus under laboratory conditions proved to be sufficient to provide significant phytotoxicity, and the relative role of parthenin to overall phytotoxic effects of the crude extract could be estimated to $16-100 \%$. Thus, current findings provide evidence that the release of parthenin during decay of leaves is not the only toxic principle in the overall phytotoxicity of decomposing leaf material, but has the capacity to play a leading role. If 
this laboratory potential may play a substantial role in the interference of $P$. hysterophorus with surrounding plant species in nature, it will be governed by several influencing factors.

The observed variability of parthenin content in leaf extracts suggests that a major contribution will be restricted to situations in which parthenin dominates the spectrum of inhibitors released from leaf material. Considering that the rate of release of allelochemicals from decomposing residues is proportional to the total amount present within the residues, one could assume that parthenin will be the determining factor for residue allelopathy only if high levels are accumulated in the leaf material. Whether the leaf litter that naturally accumulates on the soil surface contains effective levels of parthenin is unknown, since little emphasis has so far been placed on the production dynamics of parthenin by $P$. hysterophorus as triggered by plant age or environmental stress. Future investigations on residue allelopathy in P. hysterophorus and its biochemical basis should consider such production dynamics and determine the levels of parthenin present in leaves that drop on the soil surface. In addition to the concentration of parthenin in plant residues, the amount of leaf litter that typically accumulates on the soil surface and the dynamics of parthenin release over time are two further factors influencing the role of parthenin in a natural setting. Kanchan and Jayachandra (1980b) reported that a dense stand of $P$. hysterophorus produces about $333 \mathrm{~g} / \mathrm{m}^{2}$ of dry leaves. Assuming a parthenin content in leaves of $2-5 \%$ of dry weight, as estimated by Rodriguez et al. (1976) and our own studies (data not shown), approximately $7-17 \mathrm{~g} / \mathrm{m}^{2}$ parthenin could be released during decomposition. Applying this amount under the conditions of the present petri dish assay, a release rate of $2-4 \%$ at one time would be sufficient to provide a parthenin concentration reaching the $\mathrm{ED}_{90}$-value for root growth of the most insensitive species $A$. conyzoides, and 5-12\% would be sufficient to observe the same effect for the most insensitive species in bioassay L. sativa. If these release rates prove true, a dense stand of $P$. hysterophorus should provide enough leaf litter that decomposition of parthenin-containing residues may add effective concentrations of parthenin to soils. Future investigations should therefore as well concentrate on quantities of leaf residues under $P$. hysterophorus stands, the dynamics for parthenin to be released 
from residues under various environmental conditions, and the phytotoxicity and stability of this phytotoxin in a soil environment.

The findings demonstrated that parthenin is among other inhibitors relevant for residue allelopathy as simulated under laboratory conditions by delaying germination and reducing plant growth. However, observed hormetic effects and variations in leaf parthenin contents or relative contribution levels suggest that possible implications for the interference of $P$. hysterophorus in a natural plant community will greatly rely on accumulation of the compound and the stability of high concentrations of parthenin in the soil.

\section{References}

Batish et al., 1997 D.R. Batish, K.H. Kohli, H.P. Singh and D.B. Saxena, Studies on herbicidal activity of parthenin, a constituent of Parthenium hysterophorus, towards billgoat weed (Ageratum conyzoides), Curr. Sci. 73 (1997), pp. 369-371.

Batish et al., 2002a D.R. Batish, H.P. Singh, D.B. Saxena and R.K. Kohli, Weed suppressing ability of parthenin — a sesquiterpene lactone from Parthenium hysterophorus, NZ Plant Prot. 55 (2002), pp. 218-221.

Batish et al., 2002b D.R. Batish, H.P. Singh, R.K. Kohli, D.B. Saxena and S. Kaur, Allelopathic effects of parthenin against two weedy species, Avena fatua and Bidens pilosa, Environ. Exp. Bot. 47 (2002), pp. 149-155.

Belz and Hurle, 2004 R.G. Belz and K. Hurle, A novel laboratory screening bioassay for crop seedling allelopathy, J. Chem. Ecol. 30 (2004), pp. 175-198.

Brain and Cousens, 1989 P. Brain and R. Cousens, An equation to describe dose responses where there is stimulation of growth at low doses, Weed Res. 29 (1989), pp. 93-96.

Datta and Saxena, 2001 S. Datta and D.B. Saxena, Pesticidal properties of parthenin (from Parthenium hysterophorus) and related compounds, Pest Manage. Sci. 57 (2001), pp. $95-101$.

De la Fuente et al., 2000 J.R. De la Fuente, M.L. Uriburu, G. Burton and V.E. Sosa, Sesquiterpene lactone variability in Parthenium hysterophorus L, Phytochemistry 55 (2000), pp. 769-772. 
Finney, 1978 D.J. Finney, Statistical method of biological assay (third ed), Charles Griffin, London (1978).

Kanchan and Jayachandra, 1979a S.D. Kanchan and Jayachandra, Allelopathic effects of Parthenium hysterophorus L. I. Exudation of inhibitors through roots, Plant Soil $\mathbf{5 3}$ (1979), pp. 27-35.

Kanchan and Jayachandra, 1979b S.D. Kanchan and Jayachandra, Allelopathic effects of Parthenium hysterophorus L. III. Inhibitory effects of the weed residue, Plant Soil $\mathbf{5 3}$ (1979), pp. 37-47.

Kanchan and Jayachandra, 1980a S.D. Kanchan and Jayachandra, Allelopathic effects of Parthenium hysterophorus L. Part IV. Identification of inhibitors, Plant Soil 55 (1980), pp. 67-75.

Kanchan and Jayachandra, 1980b S.D. Kanchan and Jayachandra, Allelopathic effects of Parthenium hysterophorus L. Part II. Leaching of inhibitors from aerial vegetative parts, Plant Soil 55 (1980), pp. 61-66.

Kohli and Batish, 1994 R.K. Kohli and D.R. Batish, Exhibition of allelopathy by Parthenium hysterophorus L. in agroecosystems, Trop. Ecol. 35 (1994), pp. 295-307.

Kohli et al., 1996 R.K. Kohli, D. Rani, H.P. Singh and S. Kumar, Response of crop seeds towards the leaf leachates of Parthenium hysterophorus L, Ind. J. Weed Sci. 28 (1996), pp. 104-106.

Kumari and Kohli, 1987 A. Kumari and R.K. Kohli, Autotoxicity of ragweed parthenium (Parthenium hysterophorus), Weed Sci. 35 (1987), pp. 629-632.

Marquardt, 1963 D.W. Marquardt, An algorithm for least squares estimation of nonlinear parameters, J. Soc. Ind. Appl. Math. 2 (1963), pp. 431-441.

Mersie and Singh, 1987 W. Mersie and M. Singh, Allelopathic effects of parthenium (Parthenium hysterophorus L.) extract and residue on some agronomic crops and weeds., J. Chem. Ecol. 13 (1987), pp. 1739-1747.

Olofsdotter et al., 2002 M. Olofsdotter, M. Rebulanan, A. Madrid, W. Dali, D. Navarez and D.C. Olk, Why phenolic acids are unlikely primari allelochemicals in rice, J. Chem. Ecol. 28 (2002), pp. 229-242. 
Pandey, 1994a D.K. Pandey, Inhibition of Salvinia (Salvinia molesta Mitchell) by parthenium (Parthenium hysterophorus L.). I. Effect of leaf residue and allelochemicals, J. Chem. Ecol. 20 (1994), pp. 3111-3131.

Pandey, 1994b D.K. Pandey, Inhibition of Salvinia (Salvinia molesta Mitchell) by parthenium (Parthenium hysterophorus L.). II. Relative effect of flower, leaf, stem, and root residue on salvinia and paddy, J. Chem. Ecol. 20 (1994), pp. 3123-3131.

Pandey, 1996 D.K. Pandey, Phytotoxicity of sesquiterpene lactone parthenin on aquatic weeds, J. Chem. Ecol. 22 (1996), pp. 151-160.

Pandey, 1993a D.K. Pandey, L.P. Kauraw and V.M. Bhan, Inhibitory effect of parthenium (Parthenium hysterophorus L.) residue on growth of water hyacinth (Eichornia crassipes Mart Solms.). I. Effect of leaf residue, J. Chem. Ecol. 19 (1993), pp. 2651-2662.

Pandey, 1993b D.K. Pandey, L.P. Kauraw and V.M. Bhan, Inhibitory effect of parthenium (Parthenium hysterophorus L.) residue on growth of water hyacinth (Eichornia crassipes Mart Solms.). II. Relative effect of flower, leaf, stem, and root residue, J. Chem. Ecol. 19 (1993), pp. 2663-2671.

Petersen et al., 2001 J. Petersen, R. Belz, F. Walker and K. Hurle, Weed suppression by release of isothiocyanates from turnip-rape mulch, Agron. J. 93 (2001), pp. 37-43. Picman and Towers, 1982 A.K. Picman and G.H.N. Towers, Sesquiterpene lactones in various populations of Parthenium hysterophorus, Biochem. Syst. Ecol. 10 (1982), pp. $145-153$.

Picman et al., 1980 A.K. Picman, G.H.N. Towers and P.V.S. Rao, Coronopilin-another major sesquiterpene lactone in Parthenium hysterophorus, Phytochemistry 19 (1980), pp. 2206-2207.

Picman and Picman, 1984 J. Picman and A.K. Picman, Autotoxicity in Parthenium hysterophorus and its possible role in control of germination, Biochem. Syst. Ecol. 12 (1984), pp. 287-292.

Reinhardt et al., 2004 C. Reinhardt, S. Kraus, F. Walker, L. Foxcroft, P. Robbertse and K. Hurle, The allelochemical parthenin is sequestered at high level in capitate-sessile trichomes on the leaf surface of Parthenium hysterophours, J. Plant Dis. Prot. XIX (2004), pp. 253-261. 
Rodriguez et al., 1976 E. Rodriguez, M.O. Dillon, T.J. Mabry, J.C. Mitchell and G.H.N. Towers, Dermatologically active sesquiterpene lactones in trichomes of Parthenium hysterophorus L. (Compositae), Experientia 32 (1976) 326-238.

Schabenberger et al., 1999 O. Schabenberger, B.E. Tharp, J.J. Kells and D. Penner, Statistical tests for hormesis and effective dosages in herbicide dose response, Agron. J. 91 (1999), pp. 713-721.

Singh and Sangeeta, 1991 S.P. Singh and Sangeeta, Allelopathic potential of Parthenium hysterophorus L, J. Agron. Crop Sci. 167 (1991), pp. 201-206.

Singh et al., 2003 D.R. Singh, D.R. Batish, J.K. Pandher and R.K. Kohli, Assessment of allelopathic properties of Parthenium hysterophorus residues, Agric. Ecosyst. Environ. 95 (2003), pp. 537-541.

Srivastava et al., 1985 J.N. Srivastava, J.P. Shukla and R.C. Srivastava, Effect of Parthenium hysterophorus Linn. extract on the seed germination and seedling growth of barley, pea and wheat, Acta Bot. Indica 13 (1985), pp. 194-197.

Streibig, 1988 J.C. Streibig, Herbicide bioassay, Weed Res. 28 (1988), pp. 479-484.

Streibig et al., 1995 J.C. Streibig, A. Walker, A.M. Blair, G. Anderson-Taylor, D.J.

Eagle, H. Friedländer, E. Hacker, W. Iwanzik, P. Kudsk, C. Labhart, B.M. Luscombe, G. Madafiglio, P.C. Nel, W. Pestemer, A. Rahman, G. Retzlaff, J. Rola, L. Stefanovic, H.J.M. Straathof and E.P. Thies, Variability of bioassays with metsulfuron-methyl in soil, Weed Res. 35 (1995), pp. 215-224. Towers et al., 1977 G.H.N. Towers, J.C. Mitchell, E. Rodrigues, F.D. Bennett and P.V.S. Rao, Biology \& chemistry of Parthenium hysterophorus L., a problem weed in India, J. Sci. Ind. Res. 36 (1977), pp. 672-684.

Corresponding author. Tel.: +49 711459 3444; fax: +49 7114592408 . 